\title{
Recommendations for design elements of doctoral programs to enhance dissertation completion rates
}

\author{
Azad Ali, Capella University, azad.ali@capella.edu \\ Shardul Pandya, Capella University, Shardul.Pandya@capella.edu
}

\begin{abstract}
Doctoral completion rates - the rate at which students complete their doctoral degrees as a proportion of students who enroll - is a topic often discussed in doctoral programs. The intended outcomes of the discussion (naturally) are to (a) reach a plan that increases the number of students completing their doctoral degrees and thus increase their graduation rates, and (b) a decrease in the doctoral attrition rate. The discussions often lead to studying factors that enhances graduation rates. Included among these factors is the design of a program focused on factors that could contribute to such goals.

This paper is about making recommendations for the design of doctoral programs and contribute to enhancing the completion rates among their students. The paper uses a model that is known for having elements in its design that are helpful in attaining the goal of increasing completion rates among doctoral students. This model recommends constructs in the design of the program that are favorable to the goal of increasing degree completion rates. This paper takes the model a step further: it takes the constructs in the model and determines design elements in the construct that are helpful with maintaining higher completion rates among the students. The paper then makes a final recommendation in combined table format that specifies the favorable elements in the design of the doctoral programs that are helpful to enhancing completion rates.
\end{abstract}

Keywords: Doctoral attrition, dissertation completion rates, doctoral completion factors

\section{Introduction}

Doctoral attrition and doctoral graduation rates are two opposing concepts that are both subject to a wide range of discussion among research studies and academies in doctoral programs. The main points of findings in these studies include the following:

- The attrition rate in these programs is high (Ali \& Kohun, 2007, Devos et al., 2017, Ellis \& Ley, 2012, Lovitts, 2009, Salter, 2019)

- The main point that leads to doctoral attrition is the difficulty faced writing doctoral dissertation (Faryadi, 2018, Gardner, 2009, Lee, 2019, 2020, Leeds et al., 2013)

- Factors in the design of the program can lead to enhancing doctoral completion rates and to minimize doctoral attrition (Breitenbach, 2019, Bloomberg, 2018, Ewing et al., 2012, Gau et al., 2020, Young, McGrath \& Filiault, 2009)

- It will be helpful to examine the design of doctoral programs to assess the availability of these helpful factors in the design of the program (Lovitts, 2008, Pappa, Elomaa \& Pera;a-Littuen, 2020, Stracke \& Kumar, 2020, Sverdilk, Hall \& McAlpine, 2020) 


\section{Issues in Information Systems}

Volume 22, Issue 3, pp. 129-144, 2021

This study is to discuss elements in the design of doctoral programs that are helpful in enhancing completion rates and minimizing attrition rates among doctoral students. The study uses the Ewing model (Ewing 2012) and takes it a step further. It studies the constructs of the model and suggests design elements in the program that are helpful to the goal of enhancing doctoral completion rates. The remainder of the paper is divided into the following sections:

- First, the frameworks followed in this paper are introduced.

- The second section is a literature review, to introduce what has been studied before on this topic and further discuss points that are favorable to enhancing doctoral completion rates.

- Discussion is introduced about the design elements that are favorable and the rank order that we deem important to have in the program design.

- Finally, a recommendation about the intended model is presented.

\section{Framework of the Study}

This paper uses two frameworks to arrive at the recommendation that we make in the study. The first is called the Ewing Model. The second is called "Scoping literature review". The following explains both frameworks used in the study. The section then presents the overall plan of this study.

\section{The Ewing Model}

The Ewing Model is a framework often referenced when discussing doctoral completion rates. It suggests four constructs that need to be present in the design of doctoral programs and would help enhance program completion. Figure 1 below depicts the Ewing model with its four constructs and the relationship amongst them.

The first construct in the Ewing model is about the structure of the program. A highly structured sequential configuration is suggested because it enhances program completion rates. The second construct is about the intensity of facilitation and dialogue in the program. It suggests that intense facilitation enhances communication, and the two in tandem contribute towards program completion. The third construct is around creating a forum for collaborative learning within a cohort. Collaborative work, as suggested in the model, will facilitate communication, enhance knowledge and help students complete their dissertations. The fourth and last construct deals with performance-based assessment in the program. Establishing a system that evaluates student performance based on established assessment criteria helps clarify issues, which in turn advances the learners towards degree completion.

A point to be noted here is that while identifying the four constructs sheds a light on broad design elements, these are general points. More can be achieved by further thought and scrutiny into the details of the four constructs. It is the intention of this research, by review of the literature, to find out more details about each of the four constructs. Through literature review, one can find nuances and detailed elements of each construct that are helpful in finding elements in the design of the program that are helpful to enhancing doctoral completion rates. This kind of literature review is called "Scoping literature review". 


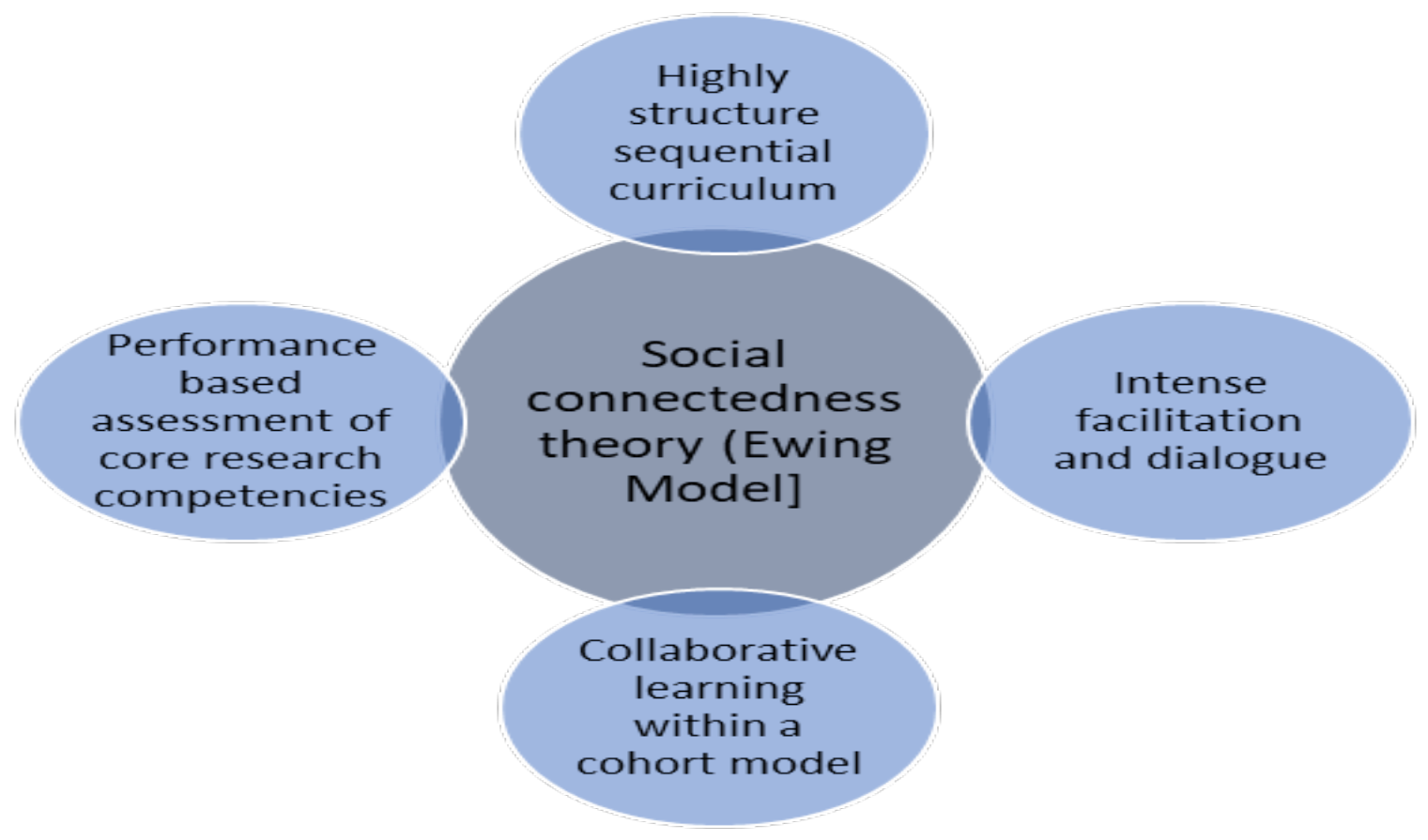

Figure 1: The Ewing Model for Doctoral Program Constructs

\section{Scoping Literature Review}

Perterson et al. (2017) explained that scoping review is a form of research methodology that allows for examination of emerging evidence. Colquhoun et al. (2017) explained that scoping reviews are used to synthesize knowledge in research and further noted that this kind of research became increasingly popular. Chang (2018) distinguished between systematic reviews and scoping reviews. While systematic reviews are more in-depth reviews, scoping reviews are used in knowledge synthesis - that is, to combine findings based on general review of literature. Tricco et al. (2016) identified three uses of scoping review findings: identify knowledge gap; establish research agenda; and clarify results for decision making process.

The point that can established from the above is that scoping reviews are used to make suggestions and synthesize knowledge based on the review in research studies. The researchers typically review literature on a topic and after the "scope", they can present a highlight, establish conclusion, give summary, and present findings (Arksey \& O’Malley, 2005, Miller and Colquhoun, 2020). This is consistent with our paper based on our plan of the study.

\section{Plan of the Study}

The goal of the study is to arrive at recommendations for missing elements of doctoral program designs as compared to the design suggested in the Ewing model. To achieve this goal, the paper goes through the following steps:

- First, we have identified the four constructs of the Ewing model.

- Second, we conduct a scoping literature review of the constructs identified. From the scoping literature review, we identify four elements that we consider most essential in the design of doctoral program to enhance degree completion rate. 
- Third, after we complete the scoping literature review and identify the essential elements, we evaluate standard doctoral programs as compared to the constructs of the Ewing model.

- After the discussion, we present our conclusion and specify the design elements that we deem helpful to enhancing doctoral dissertation completion rates. Figure 2 below shows our plan for the remainder of this study:

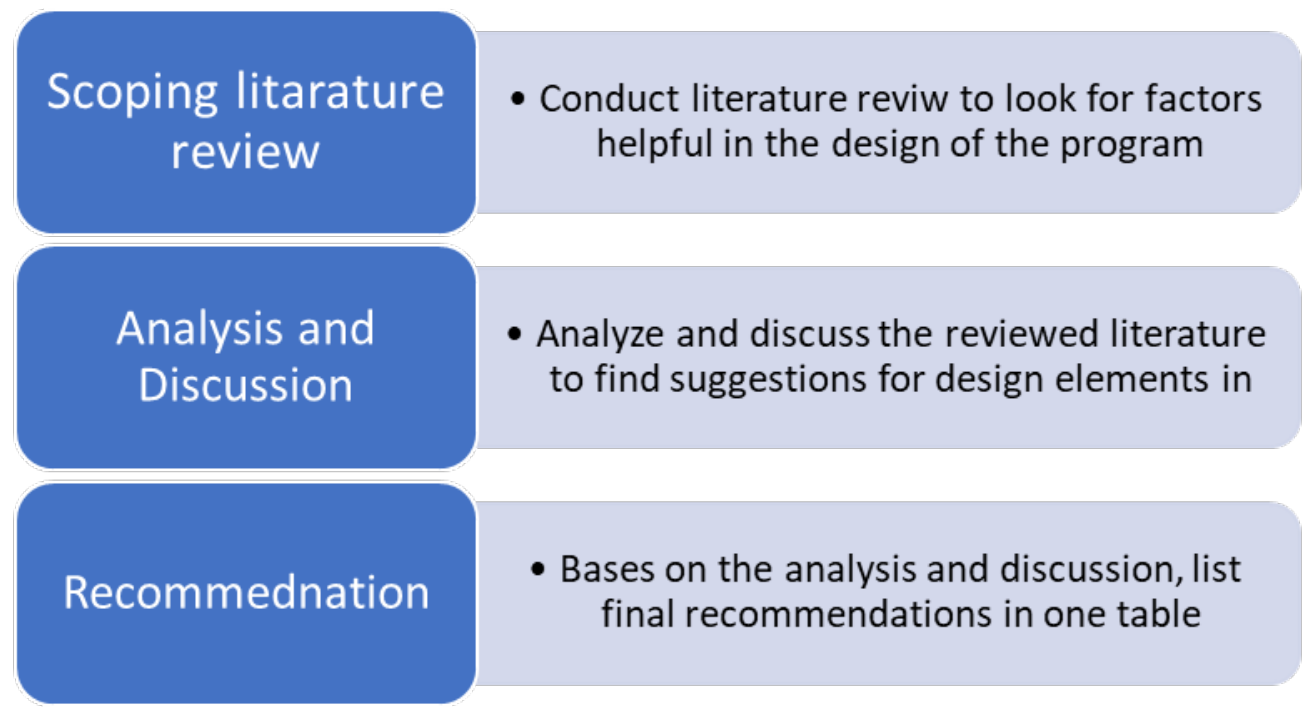

Figure 2: The Ewing Model

\section{Literature Review}

As noted earlier, the Ewing model suggests constructs for enhancing completion rates at doctoral programs. The constructs are generally included in the model with details lacking. We determined that it will be more helpful if details of the elements in the constructs are examined and further elaborated upon. This section examines the elements of the four constructs in the Ewing model. We start by explaining about the constructs in general terms. We then elaborate on these elements that are intended to enhance completion rates of doctoral dissertations.

\section{Curriculum Structure}

Different studies that have been conducted to examine factors that lead to increase doctoral completion rates suggest that lack of structure in the program design increase the likelihood for student confusion, which essentially leads to attrition and non-completion of the doctoral programs. For instance, Ewing et al., (2012) noted that a contributed factor often leading to doctoral attrition is the lack of a highly structured design of the program. Breitenbach (2019) on the other hand, explained that a lack of structure in dissertation completion leads to students dropping out of the program after reaching the "all but dissertation" or ABD phase of their study. Ames, Berman and Casteel (2018) suggested that some programs do not clearly identify the structure of their programs and thus the students are left to navigate their way through the completion of their dissertation.

It is evident that creating a structured program and identifying the sequence of courses that students must take in order to complete their dissertation will be most helpful. Indeed, for the courses that the students are 


\section{Issues in Information Systems}

Volume 22, Issue 3, pp. 129-144, 2021

expected to take, availability of course syllabus will also play an important role. In addition, it must be noted that while identifying the sequence of courses (and their syllabi) is a necessary condition, that by and of itself is not a sufficient one. In addition to a defined structure of courses, students can be helped if the program offers good documentation and communication on steps needed to be completed prior to graduation, along with the sequence and expectations at each step. Examples are expectations and eligibility for the comprehensive examination, proposal writing and its defense, and IRB approval if needed, data collection and final defense.

In academia, it is well known that a good place to start gaining knowledge about course content is through course syllabi. A course syllabus serves the purpose of clarifying course description, course objectives, course contents and sometimes assessment procedures (Willingham-McLain, 2011). Additionally, comprehensive documentation is recommended, in what is described as a coordinated syllabus development (Sweet, McElrath and Kain, 2014). An example of comprehensive documentation is the availability of course syllabi for courses that span multi-terms and are connected to previous and subsequent courses, syllabi for elective courses, documentation that includes the sequence in which courses are to be taken, differentiation between required and elective courses, and when and how many electives can be taken.

One of the commonalities among doctoral dissertations is that all dissertation documents have a similar design - most have identifiable multi-chapter document with sections and subsections identified. This should be well known to the doctoral programs since a doctoral advisor would have written one themselves. However, the same may not be clear to the students who start writing their dissertations. Or a formal structure for the dissertation document is not defined, and it is up to the student and their advisor to write it. Doctoral programs are often accused of lack of clarity on the specifics of what needed to be included in the dissertation (Lovitts, 2008, 2009). Creating a document template with clear division of chapters and sections for all students to follow will help in clarifying these issues (Sakaguchi, Arase \& Komachi, 2017).

Along the same lines, while enforcing using doctoral dissertation templates and taking advantage of wellexplained chapters in the dissertation is important, developing documentation clarifying what must be included in each section of each chapter would also be helpful. This is sometimes called a chapter guide or a dissertation guide. The purpose of such a document is to clarify what is expected to be included in each chapter and it can be used as a "guide" as the name indicates.

\section{Facilitation and Dialogue}

Facilitator, advisor, supervisor and mentor are four terms often repeated when discussing doctoral attritions or completion rates. Although the four words are not interchangeable, they have many commonalities in doctoral research studies that would justify using them here synonymously and to mean the same thing. The words refer to a form of supervising the students through completing their doctoral dissertations. In most institutions, one designated individual serves in this role, although it is conceivable for two or more people be available to help a student in this capacity.

Research stressing the importance of correct mentoring in order to successfully complete the dissertation and to improve doctoral completion rate and to minimize doctoral attrition is plentiful (Brill et al., 2014, Ewing et al., 2016, Maor, Ensor \& Fraser 2016, Lee, 2019, Orelano et al., 2016). Brill et al. (2014) noted that the most critical factor that affects doctoral student completion rate is effective faculty mentorship. Brill noted further that one of the main causes of lack of persistence among doctoral students is the absence of effective mentoring from faculty. 


\section{Issues in Information Systems}

Volume 22, Issue 3, pp. 129-144, 2021

Ewing et al. (2012) took it a step further and noted that lack of effective facilitation could lead to the notorious ABD status. Maor (2016) emphasized that supervision of doctoral students through dissertation completion needs to be improved in order to increase doctoral completion rates. Breitenbach (2019) suggested that one of the primary factors leading to increased doctoral completion rates is an effective relationship between the student and advisor.

The point thus established is that effective supervision leads to enhanced graduation rates. So then, the logical follow up question at this point is would be, what makes effective supervision? The question gets complicated knowing that supervision would include support that begins with formulation of the research question and carries through the dissertation journey including the formation of a committee and a working relationship with the committee. The student and advisor relationship can therefore span several semesters over a few years. The argument that stands here is that all stages of the advising process are critical. These stages include:

- $\quad$ Assigning or matching student with a supervisor

- $\quad$ Establishing rules for dialogue between the adviser and the mentor

- $\quad$ Supervision of the work throughout entire dissertation journey

- IRB approvals

- $\quad$ Addressing the critical questions, providing feedback on writing

- Inclusion of other committee members

- $\quad$ Issues regarding feedback from committee members and conflict

In their study, Orelano et al. (2016) argue that doctoral success rates can be enhanced when correctly matching students with their supervisors. The study further noted that the quality of the supervision is affected by the needs of the students, institutional requirements, resources and skills of the student as well as the identification of the supervisor roles. This also entails the discussion of the nature of the supervisory relationship that is expected to last for a few years at minimum.

Strake and Kumar (2020) suggested that the role of the advisor is subject to interpretation, and it could be understood differently. They suggested that the advisor could play the role of a teacher, a guide, a critic, a freedom giver, a motivator, a friend or any one of the other qualities required from the supervisor, switching from one role to the other as times and needs necessitate. Brill et al. (2014) were more concerned about emotional support or motivation that the mentor could provide to the student.

To start with, a key factor helpful in the matching doctoral students with advisers is that they must have a common interest in the research topic that the students is researching (Brill et. Al, 2014). But the topic of interest is not sufficient by itself for correctly matching students with supervisors. Personality factors and work styles also play a big role. This leads to the discussion of continuing the relationship between the student and the advisor throughout the stages of completing the writing of the dissertation. The critical factor in this relationship is the dialog and the feedback process (Brill et al., 2014).

Feedback from the supervisor plays a critical role in helping to complete the dissertation. Stracke and Kumar (2020) introduced the Feedback Expectation Tool (EFT) to facilitate the communication and feedback among faculty and student. Writing feedback is a contentious matter when it comes to providing it from the advisor. The feedback would certainly include opinion on writing and may incorporate grammatical corrections. However, providing full fledge writing feedback is not total responsibility of the advisor (Ames, Berman and Casteel, 2018). This leads to the discussion of availability of writing resources 


\section{Issues in Information Systems}

Volume 22, Issue 3, pp. 129-144, 2021

within the university (Lee, 2019). Some writing help could come from the university, which leads to the availability of the writing center.

A critical issue also is the formation of the committee and the working among the committee members for coordinating the review and the completion of defense, the dissertation document and essentially graduation and publication. Committee members (other than the advisor) are assigned for the review as well. This includes a new layer of communication issues: coordination between student and advisor and then, student with committee member and advisor with committee member.

\section{Collaborative Learning}

Collaborative learning was emphasized in different studies as a way to encourage communication among the students themselves and among the student and the faculty in the program. This also helps with student learning from each other. Collaborative learning could take different forms including community of practice (CoP), (Kumar, et al., 2011) community of inquiry (CoI) (Arbaugh, 2007), Doctoral Community Network (DCN) (Ames, Bermand \& Casteel, 2018) and many other unofficial and informal networks. The idea behind this kind of community forming is to have students work with each other and learn from each other. However, the idea needs to be implemented within the program, and it must be managed and supervised in order for it to bear the fruit. Without such support and structure, the efforts will be scattered and only the students who can form such groups will be able to take advantage of it.

Peer mentoring is another form of collaborative learning discussed in the literature. In peer mentoring, students work together or to mentor each other (Black, 2017). Students in advanced stage of their dissertation can be assigned to help students at earlier stage of the writing of the dissertation. If the stages are divided by years, students from senior years can be assigned to students in less advanced years. This way, junior students can be helped from the expertise of senior students.

The cohort approach receives a lot of praise in different studies (Drago-Seversion et al., 2001, Maher, 2005, Columbaro, 2009). In the cohort approach, a group (or cohort) of students enroll into and begin the program at the same time. They enroll in the same courses and move through the required course sequence over the next few years in lock step, with little to no room for deviation. The only exception to this expectation is when a student fails a course or drops out and restarts the program at a later date (Drago-Seversion et al., 2001, Maher, 2005). This is called a "lock step" process. There are numerous benefits to this approach. The most notable benefit is the student bonding (Columbaro, 2009) and the advantages that result from it. Students in a cohort become familiar with each other as they progress, are all at the same stage of completion, have a lot of commonalities, can share work together and can cheer and console each other as individuals meet their respective goals.

Such collaboration helps with scholarly writing as well. Ewing et al. (2012) write to the challenge facing the development of scholarly writing skills that are necessary to write doctoral dissertations and publish in peer-reviewed journals. They noted further that some students struggled with extensive formatting rules such as American Psychological Association (APA) rules. Collaborative work and collaborative research help with these challenges (Reeves, Herrington \& Oliver, 2004). Collaborative research can take the form of faculty to faculty, faculty to student and student to student collaboration (Kleck \& Barnes, 2011). Students and faculty work together to complete a paper, submit it for journals/conferences and publish together. Some doctoral programs organize their own conferences and publish their own journals. Establishing journals by the doctoral university could pave the way for more collaboration, more publication and could serve as a mini stage for publication. Additionally, many academic conferences 


\section{Issues in Information Systems}

Volume 22, Issue 3, pp. 129-144, 2021

accept student submissions in the form of student-papers, which have a lower threshold for acceptance. These avenues give students exposure towards writing and submitting scholarly work for review and publication while they are still in the early stages of their doctoral journey. Early success from these efforts serves to increase a student's confidence and boost their desire to graduate.

\section{Performance Based Assessment}

Performance assessment is often discussed at a course level as well as at the program completion level. In a doctoral dissertation, performance assessment can get more complicated. The longevity of the dissertation brings other variables into consideration. Writing and approving the dissertation at different junctures can be divided into clear stages. Progress then can be judged by completing the stages, sometimes referred to as milestones (Ali \& Kohun, 2007). The clarity of the stages gives the student a wider view on what is finished, what is to be worked on now at the present time, and what is left to complete. Based on this, a timeline towards graduation can be established.

Aside from demonstrating clear expectations, performance-based assessment can explain how the grade earned in a course or a stage is based on student performance (Senter, 2017). However, the issue here is more about standardizing assessments and ensuring that they are uniformly followed. If clear expectations are established and communicated, both students and faculty would know what those are, and faculty would be expected to provide consistent feedback between when evaluating student work.

One way of doing this is through the establishment of standardized rubrics that gauge the work of the students (Saprrow, 2004). We argue that establishing rubrics for each stage of the dissertation completion process provide the students a clearer picture of what is expected of them as they progress through the journey. This is a helpful mode of assessment that helps with the completion of different stages of the dissertation.

One of the aspects of grading procedures that is often discussed in academia is feedback (Bayerlein, 2014, Wang \& Li, 2011). It behooves faculty to provide good and effective feedback on what is submitted to them for review - may it be an exam, paper, project or any other assignment or assessment - within a reasonable time. Timely feedback is crucial in completing doctoral dissertations. However, while this is an expectation, faculty are rarely held accountable for not delivering on this expectation.

Doctoral students can suffer because of lack of good and timely feedback. A doctoral dissertation is divided into stages that are interconnected, with sections that build on prior sections. Delaying feedback or providing insufficient or poor-quality feedback is liable to affect the progress of the students and may lead to lack of alignment between the early and latter stages of a thesis.

A major goal of doctoral dissertation completion is the transformation to independent research. Lovitts (2008) noted that the student is morph from being a course taker to an independent researcher by the time they have completed their dissertation. The journey to completing doctoral dissertation usually culminates with a document that is published, and it could be recognized and referenced among the research community. Additionally, most doctoral students follow their thesis up with journal publications based on their research in short order. This kind of transformation needs to be supervised and organized to ensure adherence to standards, conventions and other myriad regulations. 


\section{Discussion and Analysis}

The literature review yielded wide range of information about program design from the four constructs specified by the Ewing model. Digging deeper into what were noted in the literature reviews could produce grouping and alignments to emphasize key points in the discussion. To develop key points, certain method(s) need to be followed. Denzin and Lincoln (2000) suggested three methods of finding key points related to a particular subject: a) keyword count; b) keyword in context, and c) direct statement from experts. This section is going to use keyword in context method in order to discuss and analyze what was explained in the literature review. We will provide the discussion for the four constructs specified in the literature review and at the end we list the key points grouped from analyzing the literature review for that section.

\section{Curriculum Structure}

We agree with the Ewing model that curriculum structure is very important in enhancing completion rates of doctoral dissertations and thus was placed first in the list. We do not have direct data that attribute increasing the $\mathrm{ABD}$ numbers to lack of or inadequate curriculum structure. But the logic leads to this understanding: a structure curriculum is helpful in identifying what needs to be completed and vise versa. To echo what was noted in the two studies by Breitenbach (2019) and by Ames, Berman and Casteel (2018), a well-placed structure would draw a clearer "look ahead" of what needs to be completed, and this in turn would improve the dissertation completion rate. Thus, a clear program structure and curriculum sequence would contribute to improving dissertation completion rate.

Clearly designed course syllabi would clarify a lot about the courses and this typically serves as the gateway to gaining knowledge about a course. When a course is connected to other courses, the importance of providing clear course syllabi across the program plays more importance for courses that span multiple terms and are to be taken in a specified sequence. This is the case with dissertation courses. Completing dissertations typically takes multiple courses that feed into each other. We agree with points made by Sweet, McElrath and Kain (2014) that coordinated syllabus development is helpful to clarifying about dissertation courses and could contribute to enhancing the completion rates.

Standardized template documents are helpful in many ways. They give same familiar look across the different students who are completing the documents so similar terminology can be exchanged. It makes students "think-alike" and it could work as a yardstick to measure progress in the course. We are in full agreement with Lovitts $(2008,2009)$ that lack of clarity of doctoral dissertation hurts progress, and that providing a standardized template document followed by all students helps with the clarification.

Although it is established that doctoral dissertations for the most part contain five chapters, what goes into each chapter is subject to interpretation. This variance in explanation could be a source of confusion for the students. Thus, having a document that specifies and explains what goes in each chapter is helpful in solving this confusion. A standardized dissertation or chapter guide can assist in establishing this and could help with improving completion rates for doctoral dissertations.

Based on the review provided in this section, we grouped what we found in the literature review into four key points that could contribute to enhancing program structure in a way that helps with improving dissertation completion rates. In order of their priority, these four factors are: 


\section{Issues in Information Systems}

Volume 22, Issue 3, pp. 129-144, 2021

1. Clear program structure and curriculum sequence.

2. Coordinated course syllabus or syllabi.

3. Available dissertation templates.

4. Chapter/section guide document.

\section{Facilitation and Dialogue}

Facilitating doctoral dissertations requires supervision, guidance and direction from someone who is familiar with the process. This kind of supervision comes from an advisor, a mentor or any other similar names. Aside with the familiarity with the process, there is the issue of personality congruences. Matching an advisor with a doctoral student when there are personality clashes could more likely increases the chance of non-completion. So, there need to consider factors that lead to good matching between the student and the advisor. Thus, we are in full agreement with Orelano et al. (2016) that correctly matching student with advisors could lead to enhance the rates of successful completion of doctoral dissertation.

The initial assignment of the advisor with the student has to consider that both are going to work on the dissertation typically for lengthy period of time. During the lengthy advising time, conflicts are liable to arise and establishing some mechanism for resolving conflicts would help complete the dissertation process. Thus, we voice our agreement with Brill et al. (2014) that inappropriate or lack of mechanism to solve such conflicts could result in lowering the completion rate of doctoral dissertations.

Along the journey between the student and the advisor, feedback is also required, that is, students want feedback from the advisor. But what kind of feedback is required from the advisor and what lines to draw between what is required and what is not required? For example, is the advisor required to provide feedback about grammar and sentences corrections or formatting when there is another side in this process that checks the dissertation document for these issues. We agree with Stracke and Kumar (2020) that clarifying the role of the advisor could help in the completion rate of doctoral dissertations.

Similar to the issues of assigning advisor, there are issues for assigning committee members. Committee members could play less of a role than the advisor and assigning committee members often comes after assigning the advisor. However, committee members play a significant role in the dissertation journey. Therefore, establishing guidelines for assigning them could help with enhancing dissertation completion rates.

Based on the above discussion, we consider the following four factors that would contribute to enhancing the facilitation of the dialogue in order to improve dissertation completion rates:

1. Mechanism for assigning or matching student with a supervisor

2. Establishing rules for dialogue between the adviser and the mentor

3. Addressing the critical questions of providing feedback on writing

4. The issues regarding the inclusion of other committee members

\section{Collaborative Learning}

Collaborative learning means work completed collaboratively between more than one individual and often references articles submitted to conferences or journals for potential publications. Collaborative learning can take place between students and faculty. It could take the form of work completed collaboratively 


\section{Issues in Information Systems}

Volume 22, Issue 3, pp. 129-144, 2021

among faculty themselves. Student also can work collaboratively to complete projects. But in order for this kind of collaborative work to be successful, there has to be an established mechanism that encourages and supports this kind of work. This kind of mechanism can be achieved through the formation of official groups called community of practice, inquiry or research.

The learning must not only come from the advisor to the student. Students can help each other. This is often called "peer mentoring". Sometimes, this kind of mentoring happens without outside intervention. But when it takes place with the encouragement of the program, it is more likely to take place and it is more likely to be effective. Thus, this kind of mentoring can be helped some establishment mechanism by the program. We are in full agreement with Ali and Kohun (2007) when they opine that forming these kinds of groups is more likely to help with completing the dissertation.

Forming doctoral classes and aligning the students to take classes together takes different forms. One of these forms is called the cohort approach. In the cohort approach, the same group of students take classes together and potentially complete the dissertation with the same time frame. It is undoubtedly clear that forming cohorts to complete the doctoral journey is helped through the forming of cohorts. The students develop bonds when they work in a cohort. But the cohort need to be encouraged by the program to work together in order to help each other complete the dissertation.

One point that is shared among doctoral programs is that all of them want to graduate researchers. To help in producing researchers, it will be helpful if the faculty in the program are prolific in research. One way of help the prolific researcher/faculty, is through collaborative research - this faculty working with faculty to write and publish articles. This kind of collaboration is transferred to the students and in turn help with completing the dissertation.

Based on the discussion above, we identified four factors that could contribute to enhancing collaborative learning and then enhancing completion rates among doctoral students. These four factors are:

1. Community of practice/inquiry/research

2. Peer mentoring

3. Cohort approach

4. Collaborative research among faculty

\section{Performance Based Assessment}

As noted earlier, completing the doctoral dissertation is likely to take the students through different stages. It will be helpful to complete the dissertation if there are clear expectations spelled out about what is required in each stage. We agree with Ali and Kohun (2007) that establishing a yardstick that signifies the completion of stages (sometimes called milestones) is a factor that can help enhance the completion rate of dissertations.

Similarly, clear metrics that gauge completion at each stage or milestone will be helpful. The clear expectations can come in the form of a rubric and additional documentations that help clarify what is expected at the specified stage. Specific helpful guide is to develop documentations for each of the five chapters in the dissertation. 


\section{Issues in Information Systems}

Volume 22, Issue 3, pp. 129-144, 2021

As noted, completing the doctoral dissertation required going through stages. Within each stage, student could submit multiple documents in order to satisfy the requirements at the specified stage. There has to be some mechanism that govern the feedback provided to the students. This requirement can specify length of time, depth of feedback and other requirements.

Completing doctoral dissertation often requires submitting the dissertation for publication. The requirement for publications could be different from what is practiced during the advising process. We are in agreement that if the program provides the students help with sending the dissertation for publication would help correctly submitting it and eventually helps with enhancing completion rate.

Based on our discussion and our analysis of what is listed for the performance-based assessment section of the literature review, we identified four factors in the design of the program that could contribute to successful completion of the doctoral dissertation:

1. Clear stage expectations

2. Rubric based assessment

3. Timely response

4. $\quad$ Finalizing and publishing procedures

\section{Recommendations}

Based on a detailed literature review and the analysis that we provided in the previous sections we present our final recommendations about the design elements in doctoral program design. These design elements are favorable to enhancing doctoral dissertation completion rates. Table 1 below is a depiction of these design elements in one place. It is divided into four areas that are consistent with the constructs specified in the Ewing model. The first column typed vertically to make it easier to present it under one group. Then the construct elements and the rank that we consider important to be included in the design of the program to help with completion rates. 


\section{Issues in Information Systems}

Volume 22, Issue 3, pp. 129-144, 2021

Table 1: Summary of evaluation of Design Elements of the doctoral dissertation program

\begin{tabular}{|c|c|c|c|c|c|}
\hline \multirow{5}{*}{$\begin{array}{c}\text { Curric } \\
\text { ulum } \\
\text { Struct } \\
\text { ure } \\
\text { Const } \\
\text { ruct } \\
\text { Evalu } \\
\text { ation }\end{array}$} & Construct element & Rank & Construct Element & Rank & \multirow{5}{*}{$\begin{array}{c}\text { Facilit } \\
\text { ation } \\
\text { and } \\
\text { dialog } \\
\text { ue } \\
\text { const } \\
\text { ruct } \\
\text { evalu } \\
\text { ation }\end{array}$} \\
\hline & $\begin{array}{l}\text { Program structure and } \\
\text { curriculum sequence }\end{array}$ & 1 & $\begin{array}{l}\text { Assigning or matching student } \\
\text { with a supervisor }\end{array}$ & 1 & \\
\hline & Coordinated course syllabus & 2 & $\begin{array}{l}\text { Establishing rules for dialogue } \\
\text { between adviser and mentor }\end{array}$ & 2 & \\
\hline & Available templates & 3 & $\begin{array}{l}\text { Addressing the critical } \\
\text { questions of providing } \\
\text { feedback on writing }\end{array}$ & 3 & \\
\hline & Chapter/section guide & 4 & $\begin{array}{l}\text { The issues regarding the } \\
\text { inclusion of other committee } \\
\text { members }\end{array}$ & 4 & \\
\hline \multirow{5}{*}{$\begin{array}{c}\text { Colla } \\
\text { borati } \\
\text { ve } \\
\text { Work } \\
\text { Const } \\
\text { ruct } \\
\text { Evalu } \\
\text { ation }\end{array}$} & Construct Element & Rank & Construct Element & $\begin{array}{l}\text { Our } \\
\text { Score }\end{array}$ & \multirow{5}{*}{\begin{tabular}{|c} 
Perfo \\
rman \\
ce \\
based \\
asses \\
smen \\
$t$ \\
const \\
ruct \\
evalu \\
ation
\end{tabular}} \\
\hline & $\begin{array}{l}\text { Community of } \\
\text { practice/inquiry/research }\end{array}$ & 1 & Clear stage of completion & 1 & \\
\hline & Peer mentoring & 2 & Rubric based assessment & 2 & \\
\hline & Cohort approach & 3 & Timely response & 3 & \\
\hline & $\begin{array}{l}\text { Collaborative research } \\
\text { among faculty }\end{array}$ & 4 & $\begin{array}{l}\text { Mechanism for research } \\
\text { completion \& publication }\end{array}$ & 4 & \\
\hline
\end{tabular}

\section{References}

Ali, A., \& Kohun, F. (2007). Dealing with Social Isolation to Minimize Doctoral Attrition -- A Four Stage Framework. International Journal of Doctoral Studies, 2, 33-49. https://doi.org/10.28945/56

Ames, C., Berman, R., \& Casteel, A. (2018). A preliminary examination of doctoral student retention factors in private online workspaces. International Journal of Doctoral Studies, 13(1), 79-107.

Arbaugh, J. B. (2007). An empirical verification of the community of inquiry framework. Journal of Asynchronous Learning Networks, 11(1), 73-85.

Arksey, H., \& O'Malley, L. (2005). Scoping studies: towards a methodological framework. International journal of social research methodology, 8(1), 19-32.

Bayerlein, L. (2014). Students' feedback preferences: how do students react to timely and automatically generated assessment feedback?. Assessment \& Evaluation in Higher Education, 39(8), 916-931. 


\section{Issues in Information Systems}

Volume 22, Issue 3, pp. 129-144, 2021

Black, R. (2017). E-mentoring the online doctoral student from the dissertation prospectus through dissertation completion. Journal of Learning in Higher Education, 13(1), 1-8.

Bloomberg, L. D., \& Volpe, M. (2018). Completing your qualitative dissertation: A road map from beginning to end. Sage Publications.

Breitenbach, E. (2019). Evaluating a model to increase doctorate program completion rates: A focus on social connectedness and structure. International Journal of Doctoral Studies, 14(1).

Brill, J. L., Balcanoff, K. K., Land, D., Gogarty, M., \& Turner, F. (2014). Best Practices in Doctoral Retention: Mentoring. Higher Learning Research Communications, 4(2), 26-37.

Chang, S. (2018). Scoping reviews and systematic reviews: is it an either/or question?. Annals of internal medicine, 169(7), 502-503.

Columbaro, N. L. (2009). e-Mentoring possibilities for online doctoral students: A literature review. Adult Learning, 20(3-4), 9-15.

Colquhoun, H. L., Levac, D., O'Brien, K. K., Straus, S., Tricco, A. C., Perrier, L., ... \& Moher, D. (2014). Scoping reviews: time for clarity in definition, methods, and reporting. Journal of clinical epidemiology, 67(12), 1291-1294.

Denzin, N. K., \& Lincoln, Y.S. (2000). Handbook of qualitative research. Thousand Oaks, CA: Sage Publications.

Devos, C., Boudrenghien, G., Van der Linden, N., Azzi, A., Frenay, M., Galand, B., \& Klein, O. (2017). Doctoral students' experiences leading to completion or attrition: A matter of sense, progress and distress. European Journal of Psychology of Education, 32(1), 61-77.

Drago-Severson, E., Helsing, D., Kegan, R., Popp, N., Broderick, M., \& Portnow, K. (2001). The power of a cohort and of collaborative groups. Focus on Basics, 5(2), 15-22.

Ellis, T. J., \& Levy, Y. (2012). Data sources for scholarly research: towards a guide for novice researchers. In In SITE 2012: Informing Science+ IT Education Conference (Vol. 12, pp. 405-416).

Ewing, H., Mathieson, K., Alexander, J. L., \& Leafman, J. (2012). Enhancing the acquisition of research skills in online doctoral programs: The Ewing model $\mathbb{C}$. Journal of Online Learning and Teaching, 8(1), 34.

Faryadi, Q. (2018). PhD Thesis Writing Process: A Systematic Approach--How to Write Your Introduction. Online Submission, 9, 2534-2545.

Gardner, S. K. (2009). The development of doctoral students: Phases of challenge and support (special report). ASHE Higher Education Report, 34(6), 1-127. https://doi.org/10.1002/aehe.3406

Gau, K. H., Dillon, P., Donaldson, T., Wahl, S. E., \& Iwema, C. L. (2020). Partnering with postdocs: a library model for supporting postdoctoral researchers and educating the academic research community. Journal of the Medical Library Association, 480-486. https://doi.org/10.5195/jmla.2020.902 


\section{Issues in Information Systems}

Volume 22, Issue 3, pp. 129-144, 2021

Kleck, G., \& Barnes, J. C. (2011). Article productivity among the faculty of criminology and criminal justice doctoral programs, 2005-2009. Journal of Criminal Justice Education, 22(1), 43-66.

Kumar, S., Dawson, K., Black, E. W., Cavanaugh, C., \& Sessums, C. D. (2011). Applying the community of inquiry framework to an online professional practice doctoral program. International Review of Research in Open and Distributed Learning, 12(6), 126-142.

Lee, A. (2019). Successful research supervision: Advising students doing research. Routledge.

Lee, K. (2020). A Phenomenological Exploration of the Student Experience of Online PhD Studies. International Journal of Doctoral Studies, 15, 575-593.

Leeds, E., Campbell, S., Baker, H., Ali, R., Brawley, D., \& Crisp, J. (2013). The impact of student retention strategies: An empirical study. International Journal of Management in Education, 7(1-2), 2243.

Lovitts, B. E. (2008). The transition to independent research: Who makes it, who doesn't, and why. The journal of higher education, 79(3), 296-325.

Lovitts, B. E., \& Wert, E. L. (2009). Developing Quality Dissertations in the Humanities: A Graduate Student's Guide to Achieving Excellence. Stylus Publishing, LLC..

Maher, M. A. (2005). The evolving meaning and influence of cohort membership. Innovative Higher Education, 30(3), 195-211.

Maor, D., Ensor, J. D., \& Fraser, B. J. (2016). Doctoral supervision in virtual spaces: A review of research of web-based tools to develop collaborative supervision. Higher Education Research \& Development, 35(1), 172-188. https://doi.org/10.1080/07294360.2015.1121206

Miller, E., \& Colquhoun, H. (2020). The importance and value of reporting guidance for scoping reviews: A rehabilitation science example. Australian Journal of Advanced Nursing, 37(4), 53-58. https://doi.org/10.37464/2020.374.148

Pappa, S., Elomaa, M., \& Perälä-Littunen, S. (2020). Sources of stress and scholarly identity: the case of international doctoral students of education in Finland. Higher Education, 1-20.

Peterson, J., Pearce, P. F., Ferguson, L. A., \& Langford, C. A. (2017). Understanding scoping reviews: Definition, purpose, and process. Journal of the American Association of Nurse Practitioners, 29(1), 12 16.

Tricco, A. C., Lillie, E., Zarin, W., O’Brien, K., Colquhoun, H., Kastner, M., ... \& Kenny, M. (2016). A scoping review on the conduct and reporting of scoping reviews. BMC medical research methodology, 16(1), 15.

Reeves, T. C., Herrington, J., \& Oliver, R. (2004). A development research agenda for online collaborative learning. Educational Technology Research and Development, $52(4), 53$. 


\section{Issues in Information Systems}

Volume 22, Issue 3, pp. 129-144, 2021

Sakaguchi, K., Arase, Y., \& Komachi, M. (2013, August). Discriminative approach to fill-in-the-blank quiz generation for language learners. In Proceedings of the 51st Annual Meeting of the Association for Computational Linguistics (Volume 2: Short Papers) (pp. 238-242).

Salter, D. W. (2019). An Archetypal Analysis of Doctoral Education as a Heroic Journey. International Journal of Doctoral Studies, 14, 525-542.

Senter, M. S. (2017). Integrating Program Assessment and a Career Focus into a Research Methods Course. Teaching Sociology, 45(2), 131-141.

Stracke, E., \& Kumar, V. (2020). Encouraging Dialogue in Doctoral Supervision: The Development of the Feedback Expectation Tool. International Journal of Doctoral Studies, 15(1), 264-284. https://doi.org/10.28945/4568

Sweet, S., McElrath, K., \& Kain, E. L. (2014). The Coordinated Curriculum: How Institutional Theory Can Be Used to Catalyze Revision of the Sociology Major. Teaching Sociology, 42(4), 287-297.

Tricco, A. C., Lillie, E., Zarin, W., O’Brien, K., Colquhoun, H., Kastner, M., ... \& Straus, S. E. (2016). A scoping review on the conduct and reporting of scoping reviews. BMC medical research methodology, 16(1), 15.

Wang, T., \& Li, L. Y. (2011). 'Tell me what to do' vs. 'guide me through it': Feedback experiences of international doctoral students. Active Learning in Higher Education, 12(2), 101-112. https://doi.org/10.1177/1469787411402438

Willingham-McLain, L. (2011). Using a university-wide syllabus study to examine learning outcomes and assessment. The Journal of Faculty Development, 25(1), 43-53.

Young, J., McGrath, R., \& Filiault, S. (2009). Completing Your Qualitative Dissertation: A Roadmap From Beginning to End. Forum: Qualitative Social Research, 10(3), 1-10. 